\title{
ORGANIZAÇÕES DO CONHECIMENTO: PROCESSO DE GERAÇÃO DE INOVAÇÕES PARA OS SERVIÇOS NAS INSTITUIÇÕES DE ENSINO SUPERIOR
}

\author{
ODACIR MIGUEL TAGLIAPIETRA \\ ADIR OTTO SCHMIDT \\ GEYSLER FLOR BERTOLINI
}

\begin{abstract}
RESUMO: Nas organizações atuais a busca pelo conhecimento tem se tornado fator decisivo para o aumento da competitividade, pois o conhecimento gera inovações contínuas. Existem dois tipos de conhecimento: o tácito que é resultado das experiências e interesses de cada individuo, e por isso é difícil de ser comunicado de maneira formal. O conhecimento explícito, ao contrário, é aquele que pode ser armazenado em manuais e documentos, sendo acessível a todas as pessoas. As condições capacitadoras ou organizacionais necessárias para a criação do conhecimento organizacional são: Intenção, autonomia, flutuação e caos criativo, redundância e variedade de requisitos. O objetivo do trabalho foi avaliar as condições organizacionais necessárias para a criação do conhecimento organizacional. A pesquisa teve caráter exploratório. A população da pesquisa foi composta pelos funcionários técnicos administrativos do Campus da Unioeste de Cascavel, composta de 157 pessoas. Foi realizado uma tentativa de censo entre os dias 11 e 15 de maio de 2009 com retorno de 67 questionários. Os resultados da pesquisas demonstram que em todas as condições organizacionais necessárias para o funcionamento da gestão do conhecimento no Campus da Unioeste Cascavel há a necessidade de melhorias.
\end{abstract}

Palavras-chave: Gestão do conhecimento, conhecimento Tácito, conhecimento explícito

\section{INTRODUÇÃO}

Em todas as épocas as pessoas que apresentaram determinadas habilidades na realização de determinada atividade sempre teve posição de destaque, ou pela admiração ao poder criativo destas ou pelo medo que elas causavam aos que tinham o domínio sobre determinada cidade ou estado. As pessoas que possuem o domínio sobre suas vontades expressão este potencial de diferentes formas, pode ser através do desenvolvimento de uma peça de arte, na confecção de uma escultura , pela música e também na indignação em relação as estrutura social, mais especificamente, contra a opressão da maioria pelos detentores do poder.

A busca pelo conhecimento esteve presente em todas as épocas, sendo utilizado de diferentes maneiras, de acordo com as necessidades do contexto histórico. Nas organizações, o conhecimento representa uma vantagem competitiva, na medida em que estes são transformados em novos produtos ou serviços. O processo de transformação do conhecimento individual para o conhecimento organizacional requer mudanças de atitudes, e um maior comprometimento de todas as pessoas, independente do nível hierárquico. A gestão do conhecimento procura estimular a criatividade das pessoas, para criação do conhecimento organizacional.

Conforme Nonaka e Takeuchi (1997) existem cinco condições capacitadoras ou organizacionais que promovem a espiral do conhecimento. A primeira é a Intenção que representa a visão da empresa, as estratégias e os objetivos a serem alcançados. A segunda é a 
autonomia, condição necessária para as pessoas desenvolverem suas criatividades no ambiente de trabalho. A terceira condição organizacional é a flutuação e o caos criativo, a flutuação representa um colapso de rotina, fazendo com que as pessoas reconsiderem seus pontos de vistas estimulando a inovação. Esta instabilidade gera o "caos criativo" levando as pessoas a refletirem sobre qual o novo direcionamento a ser tomado. A quarta condição é a redundância que permite o compartilhamento do conhecimento tácito, fundamental no estágio inicial do desenvolvimento do conceito. E a última condição, que permite o desenvolvimento da espiral do conhecimento, é a variedade de requisitos que representa as diferentes experiências, conhecimentos e habilidades das pessoas existente na organização.

A pesquisa se caracteriza como exploratória, pois conforme Gil (1991) este tipo de pesquisa tem como objetivo proporcionar maior familiaridade com o problema, com vista a torná-lo mais explícito ou a construir hipóteses, também conforme o autor, este tipo de pesquisa tem como objetivo principal o aprimoramento de idéias ou descoberta de intuições.

O objetivo da pesquisa foi analisar as condições organizacionais necessárias para a criação de conhecimento organizacional. A população da pesquisa foram os funcionários técnicos administrativos do Campus da Unioeste de Cascavel, composta de 157 pessoas. Foi realizado uma tentativa de censo entre os dias 11 e 15 de maio de 2009 com retorno de 67 questionários.

\section{O CONHECIMENTO ATRAVÉS DOS TEMPOS}

O conhecimento sempre teve destaque em todas as épocas, seu valor depende do contexto histórico, ou seja, em cada época o conhecimento foi importante para o desenvolvimento de determinadas atividades, e sua utilização no âmbito da sociedade esteve atrelada a determinadas pessoas ou grupos.

Conforme Fritz (1989) citado por Senge (2008) ao longo da história, praticamente todas as culturas tiveram arte, música, dança, arquitetura, poesia. Contadores de história, cerâmica e escultura. O desejo de criar não é limitado por crenças, nacionalidade, credo, formação educacional ou era. $\mathrm{O}$ impulso está em todas as pessoas.

De acordo com Zabot e Silva (2002) a importância do conhecimento não é uma descoberta nova. Desde os tempos mais remotos, sabe-se que os homens que detinham muito conhecimento eram os que se destacavam dos demais. $\mathrm{O}$ grande problema foi que durante muito tempo o acesso ao conhecimento era restrito a alguns privilegiados, e o próprio conhecimento era, muitas vezes, utilizado como meio de domínio e opressão.

Esta postura se reflete no contexto organizacional, onde poucas pessoas têm a liberdade de externalizar seus conhecimentos tácitos, dificultando com isso o processo de inovação contínuo. As estruturas organizacionais rígidas e inflexíveis dificultam a criação do conhecimento organizacional, pois não apresentam as condições organizacionais adequada a livre fluxo das informações e o desenvolvimento da criatividade.

De acordo com Cavalcanti (2001), o conhecimento teve, ao longo da história diferentes significados e funções, durante a Antigüidade Clássica, o conhecimento era usado para crescimento pessoal e para aumentar a satisfação e sabedoria individual. Essa concepção sofreu uma inflexão em meados do século XVIII, justificada, em parte, pelo advento da 
revolução industrial. Com isso, o conhecimento passou a voltar-se para sua aplicação na sociedade, deixando de servir exclusivamente à satisfação pessoal. Esta modificação foi acompanhada por outra que atingiu a organização econômica da sociedade. O padrão artesanal, manual e dependente do homem foi substituído por outro de cunho industrial, tecnológico, dependente da máquina (QUIRINO, 2005).

De acordo com Colauto e Beuren (2003) a gestão do conhecimento, vista na perspectiva atual, surgiu na década de 1990, como uma proposta de agregar valor à informação e facilitar o fluxo interativo em toda corporação. Usada adequadamente, é tida como instrumento estratégico competitivo resistente ao modismo da eficiência operacional.

Segundo Sveiby (2000), citado por Colauto e Beuren (2003) o tema centra-se em aproveitar recursos existentes na empresa, proporcionando as seus integrantes empregar as melhores práticas e poupar o reinvento de processos.

O conhecimento no contexto atual é o grande diferencial para o desenvolvimento da sociedade. Os avanços tecnológicos trouxeram desenvolvimento e progresso para a humanidade, mas ao mesmo tempo, acarretou problemas em diversos setores da sociedade. Para que ocorra o desenvolvimento sustentável é necessário que as organizações estimulem as pessoas a criarem novas formas de fazer negócios que não prejudique o meio ambiente. Este tipo de postura já está sendo uma prática para a maioria das organizações, ou seja, a criação do conhecimento possibilita a inovação fundamental para a competitividade das organizações. Para ser competitivo hoje é necessário estar constantemente criando novos valores para os produtos e serviços, e isto não são apenas atributos físicos ou de qualidade, mas inclui-se também o fator social da organização

\section{IMPORTÂNCIA DO CONHECIMENTO NAS ORGANIZAÇÕES}

No atual cenário em que as organizações estão inseridas, o conhecimento é fator decisivo para a competitividade. Neste sentido, é necessário que o ambiente organizacional proporcione as condições para o livre fluxo de informações e que as pessoas sintam-se livres para desenvolver seu potencial criativo.

Existem várias definições sobre o conhecimento, de acordo com Quel (2006) conhecimento é um estado provisório de aceitação e percepção da realidade de um objeto ou evento, estado este articulado em uma estrutura cognitiva própria, gerada pela experimentação e interação do indivíduo com o ambiente no qual ele e o objeto/evento estão inseridos.

Nesse sentido, ainda segundo o autor, isso deve levar à idéia de que o conhecimento é um patrimônio individual que somente existe enquanto detido pelo seu criador e, a esta criação, denominada aprendizado, cabe o papel primordial na explicação do processo de aquisição de conhecimento.

Price Waterhouse Coopers (2000) citado por Angeloni (2002), o conhecimento é definido como um ativo intelectual, mas é mais do que os dados objetivos e explícitos encontrados nas metodologias, nos manuais ou nas patentes de uma empresa. Existe também um imenso - e talvez não reconhecido - valor na especialidade, na sabedoria e na intuição altamente subjetivas e difíceis de codificar dos funcionários.

De acordo com Terra (2005) citado por Pereira (2005) a gestão do conhecimento está, intrinsecamente, ligada à capacidade das empresas em utilizarem e combinarem as várias 
fontes e tipos de conhecimento organizacional para desenvolverem competências específicas e capacidade inovadora que se traduzem, permanentemente, em novos produtos, processos, sistemas gerenciais e liderança de mercado.

Para Coopers (2000) citado por Angeloni (2002) ,o conhecimento é definido como um ativo intelectual, mas é mais do que os dados objetivos e explícitos encontrados nas metodologias, nos manuais ou nas patentes de uma empresa. Existe também um imenso - e talvez não reconhecido - valor na especialidade, na sabedoria e na intuição altamente subjetivas e difíceis de codificar dos funcionários.

De acordo com Davenport (1998) Conhecimento é uma mistura fluída de experiências condensadas, valores, informação contextual e insight experimentado, a qual proporciona uma estrutura para a avaliação e incorporação de novas experiências e informações. Ele tem origem e é aplicado na mente dos conhecedores. Nas Organizações, ele costuma estar embutido não só em documentos ou repertórios, mas também em rotinas, processos, práticas e normas organizacionais.

A partir das diversas definições de conhecimento, percebe-se a diferença entre dois tipos de conhecimentos, o tácito e o explícito, ambos importantes e que não podem ser tratados separadamente, pois fazem parte da dinâmica do processo de criação de conhecimento.

\subsection{A dimensão tácita e explícita do conhecimento organizacional}

A dinâmica da criação do conhecimento organizacional envolve dois tipos de conhecimento: o conhecimento tácito e explícito.

De acordo com Nonaka e Takeuchi (1997) o conhecimento tácito pode ser segmentado em duas dimensões. A primeira é a dimensão tácita, que abrange um tipo de capacidade informal e difícil de definir ou habilidades capturadas no termo know-how. Um artesão, por exemplo, desenvolve uma riqueza de habilidades, suas "mãos maravilhosas" depois de anos de experiências. Mas frequentemente é incapaz de articular os princípios técnicos ou científicos subjacentes ao que sabe.

Ainda segundo os autores, ao mesmo tempo, o conhecimento tácito contém uma importante dimensão cognitiva. Consistem em esquemas, modelos mentais, crenças e percepções tão arraigadas que são tomados como certos. A dimensão cognitiva do conhecimento tácito reflete nossa imagem da realidade (o que é) e nossa visão de futuro (o que deveria ser). Apesar de não poderem ser articulados muito facilmente, esses modelos implícitos moldam a forma com que se percebe o mundo à nossa volta.

Para Polanyi (1967) citado por Angeloni (2002), o conhecimento explícito é formal e sistemático e pode ser facilmente comunicado e partilhado. Já o conhecimento tácito é altamente pessoal, de difícil formalização e comunicação. O conhecimento organizacional explícito é o conhecimento exibido em manuais de procedimentos, memórias de computador, relatórios, pesquisas; o tácito é aquele que inclui o discernimento, o instinto e a compreensão profunda dos indivíduos.

Conforme Nonaka e Takeuchi (1997) a dinâmica da criação do conhecimento ocorre a partir da interação entre conhecimento tácito e explícito. O conhecimento já existente na empresa, na maioria das vezes é aprimorado a partir de novos conhecimentos tácitos.

De acordo com Colauto e Beurmen (2003) com o enfoque da gestão do conhecimento, as empresas passaram a se preocupar com seu capital intelectual e com sua inteligência 
competitiva. Iniciando desta forma, um novo processo para rever a organização, suas estratégias, estruturas e, principalmente, a cultura organizacional. Através da gestão do conhecimento as organizações se preocupam com o conhecimento tácito e sua explicitação durante todo o ciclo de negócios.

\section{DESENVOLVIMENTO DA ESPIRAL DO CONHECIMENTO}

De acordo com Sveiby (1998) citado por Angeloni (2002), existem algumas práticas formais de compartilhamento do conhecimento - como palestras, apresentações audiovisuais, manuais e livros, propícias ao compartilhamento do conhecimento explícito, e outras, como o método "carona", quando um profissional júnior ou trainee trabalha por certo tempo com outro mais antigo para que ocorra o compartilhamento do conhecimento tácito.

Morey (2000) citado por Angeloni (2002) destaca que os trabalhadores do conhecimento não compartilharão seus conhecimentos a menos que tenham um benefício próprio. Criar uma infra-estrutura ajuda a tornar o processo mais fácil, mas sem uma cultura de compartilhamento só a captura do conhecimento trará sucesso. Os impulsos mais comuns para o compartilhamento do conhecimento são: prestígio, reconhecimento e a noção do que as idéias e os pensamentos dos indivíduos possam fazer a diferença.

De acordo com Quel (2006), é importante o entendimento de que determinado indivíduo é o único capaz de armazenar conhecimento se este é fruto do relacionamento do homem com o ambiente. Transferir conhecimento significaria ter como obrigatória a transferência de todo o âmago individual que gerou aquele conhecimento.

De acordo com Morin (1986) o conhecimento é individual, ou seja, as aptidões cognitivas humanas não podem desabrochar senão no seio de uma cultura que produziu, conservou, transmitiu uma linguagem, uma lógica, um capital de saberes e de critérios de verdade.

O conhecimento é criado a partir da conversão do o conhecimento tácito em explícito, sendo necessário, para isso, quatro modos de conversão conforme figura 1 .

\section{Conhecimento Tácito em Conhecimento Explícito}

\begin{tabular}{l|c|c|}
\cline { 2 - 3 } Conhecimento & Socialização & Externalização \\
Tácito & & \\
do & & \\
Conhecimento & Internalização & Combinação \\
\cline { 2 - 3 } Explícito & & \\
& & \\
\end{tabular}

Figura 1 - Modos de conversão do conhecimento

Fonte: Nonaka e Takeuchi (1997) 
De acordo com Nonaka e Takeuchi (1997) a criação do conhecimento organizacional é uma interação contínua e dinâmica entre o conhecimento tácito e o conhecimento explícito. Essa interação é moldada pelas mudanças entre diferentes modos de conversão do conhecimento.

A primeira fase é o modo de socialização que começa com um campo de interação onde são compartilhadas as experiências e modelos mentais dos mesmos. O segundo modo é a externalização que é provocada pelo diálogo ou pela reflexão, e com auxílio de metáforas e analogias o conhecimento tácito é transformado em um novo conceito. O terceiro modo é a combinação, que é provocado pela colocação do conhecimento recém criado ou o novo conceito ao conhecimento já existente, cristalizando-se assim, em um novo produto, serviços ou sistema gerencial. Por fim, o modo internalização é o aprender fazendo, onde o novo conceito recém criado é assimilado pelas pessoas, ou seja, o conhecimento explícito é transformado novamente em tácito.

Esse processo não acaba no último modo de conversão, ou seja, o conhecimento criado é expandido para toda a organização, e também se torna referência para outras organizações inserirem nas suas práticas o processo de inovação contínua. De acordo com Nonaka e Takeuchi (1997) essa evolução do conhecimento que começa a nível individual e acaba chegando a níveis ontológicos superiores é denominado de espiral do conhecimento, conforme apresentado na figura 2.

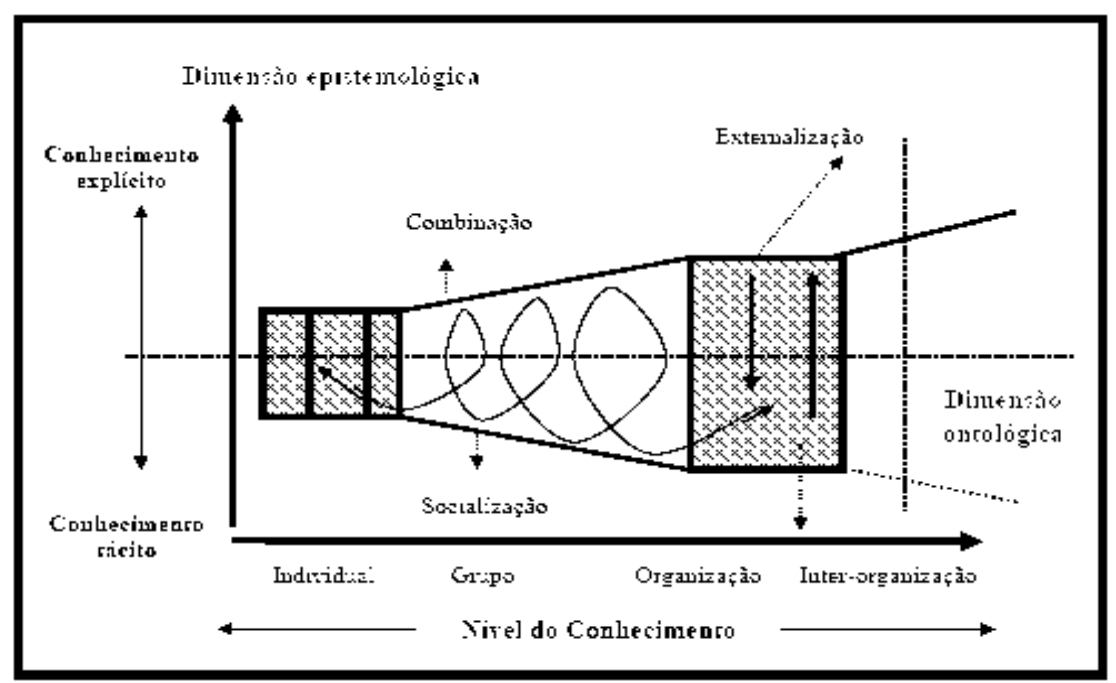

Figura 2: A espiral do conhecimento

Fonte: Nonaka e Takeuchi (1997)

\section{CONDIÇÕES ORGANIZACIONAIS PARA A CRIAÇÃO DO CONHECIMENTO ORGANIZACIONAL}

As mudanças na forma de realização do trabalho não são apenas uma troca de um sistema administrativo obsoleto para um modelo mais atualizado. Para que a implementação de novos sistemas de trabalho tenham resultado satisfatório é necessário avaliar as condições organizacionais. 
De acordo com Nonaka e Takeuchi (1997) a função da organização no processo de criação do conhecimento organizacional é fornecer o contexto apropriado para a facilitação das atividades em grupo e para a criação e acúmulo de conhecimento em nível individual. Os autores apresentam cinco condições capacitadoras ou organizacionais que facilitam a criação do conhecimento organizacional: Intenção; autonomia; flutuação e caos criativo; redundância e variedade de requisitos.

Conforme os autores, a espiral do conhecimento é direcionada pela Intenção organizacional. No contexto das organizações a Intenção assume a forma de estratégia. No entanto, do ponto de vista da criação do conhecimento organizacional a essência da estratégia está no desenvolvimento da capacidade organizacional de adquirir, criar, acumular e explorar o conhecimento. Neste sentido, a Intenção é a conceitualização da visão sobre o tipo de conhecimento que deve ser desenvolvido e operacionalizado.

Definido o tipo de conhecimento que deve ser desenvolvido, a partir da visão da empresa a proposta deve ser operacionalizada. Mas antes disso, com a aplicação da espiral do conhecimento essa proposta deverá ser discutida e analisada pelas equipes que terão a incumbência de sistematizar essa visão em forma de novos conceitos.

A segunda condição necessária para promover a espiral do conhecimento é autonomia. De acordo com os autores, no nível individual, todos os membros da organização devem agir de forma autônoma pois, idéias originais emanam de indivíduos autônomos que difundem-se dentro da equipe, transformando-se então em idéias organizacionais. A autonomia permite que indivíduos e grupos estabeleçam as fronteiras de suas tarefas por conta própria, à fim de buscar a meta definitiva expressa na mais elevada Intenção da organização.

A terceira condição necessária para promover a espiral do conhecimento são a flutuação e o caos criativo. A flutuação está relacionada às situações de instabilidade do ambiente interno e externo ou pode ser provocada pela própria empresa. Esta condição promove a criação do conhecimento, pois, conforme os autores, quando a flutuação é introduzida na organização seus membros enfrentam um "colapso" de rotinas. Desta maneira, permite que as pessoas e a organização revejam suas atitudes e sua postura diante da realidade. O colapso de rotinas permite que o diálogo seja instaurado novamente, promovendo a interação entre as pessoas na busca de novos conceitos. Portanto, essa situação de instabilidade provocada por mudanças ambientais ou quando são geradas intencionalmente pelos líderes da organização é denominado pelos autores de caos criativo, este aumenta a tensão dentro da organização e faz com que os membros da organização focalizem suas atenções na resolução do problema levando a formulação de novos conceitos.

A quarta condição organizacional é a redundância. Para a maioria das pessoas a redundância é algo desnecessário e que leva ao desperdício de tempo. Mas a redundância na concepção dos autores, na organização de negócios, refere-se à superposição intencional de informações sobre as atividades. Através do compartilhamento de informações redundantes o conhecimento tácito é compartilhado, e assim o processo de criação do conhecimento é acelerado. Ainda segundo os autores, a redundância é importante, sobretudo no estágio de desenvolvimento do conceito, quando é essencial expressar imagens baseadas no conhecimento tácito. 
A quinta condição organizacional é a variedade de requisitos. De acordo com Ashby (1956) citado por Nonaka e Takeuchi (1997), a diversidade interna da organização deve corresponder à variedade e à complexidade do ambiente para permitir que ela enfrente os desafios impostos pelo ambiente. Uma organização deve ter uma estrutura compatível com as necessidades impostas pelo ambiente interno e externo A variedade de requisitos corresponde à visão sistêmica, ou seja, todos os setores devem estar interligados utilizando-se com isso, o apoio da tecnologia, a partir de redes computadorizada de informações. Os diferentes setores e funções, composto por pessoas com conhecimentos e habilidades diferentes devem manter-se interligados para que estes conhecimentos e habilidades sejam compartilhados, facilitando assim a elaboração dos novos conceitos proposto pela intenção organizacional.

\section{GESTÃO DO CONHECIMENTO NAS ORGANIZAÇÕES PÚBLICAS}

De acordo com Silva (2000), os serviços públicos têm sofrido mudanças no mundo inteiro e também no Brasil. A sociedade exige melhor qualidade e eficiência na prestação de serviços, e para tanto, os órgãos públicos devem buscar, adaptar e implementar as melhores práticas das empresas privadas, com especial atenção para as que alavancam competências como a Gestão do Conhecimento (GC) e criar indicadores de desempenho satisfatórios.

Ainda segundo o autor, nas organizações públicas a gestão do conhecimento deve ser vista como um instrumento para buscar eliminar a ineficiência, o comodismo e contribuir para a valorização do funcionário público como trabalhador do conhecimento. $\mathrm{O}$ serviço público precisa ter seu foco voltado para o cidadão e não para si mesmo, como na maioria das instituições brasileiras. Uma prestação de serviços de qualidade à sociedade urge como necessária, deixando de lado a burocracia e os baixos desempenhos onde quer que existam na esfera pública.

Para Campos (2003) a inserção e a prática da gestão do conhecimento na administração pública não é fácil, exigindo um profundo conhecimento sobre como proceder e uma capacidade especial para motivar a colaboração das pessoas para este processo, no sentido de contribuírem com sugestões, suporte e inovações, enfim, contribuírem com o seu "saber".

Ainda segundo o autor, a dificuldade em se adotar novas práticas gerenciais, como a gestão do conhecimento, se deve, em parte, por que, tradicionalmente, a administração pública brasileira se baseia no paradigma burocrático e não no paradigma gerencial, não estando totalmente aberta às mudanças.

De acordo com Silva (2005), no setor privado o conhecimento visa proporcionar vantagem competitiva, no setor público, ele pode trazer mais eficiência, ação estratégica, serviços de qualidade, otimização e valorização dos recursos humanos. O foco passa a ser o cidadão, mudam-se os processos e a forma de se relacionar com os públicos internos e externos. Mas qual o caminho para que isso aconteça? Primeiro, é necessário compreender que o conhecimento está nas pessoas. Apenas $10 \%$ do conhecimento de uma organização são explícitos (marcas, patentes, softwares), ou seja, 90\% são tácitos (experiências, habilidades individuais) e estão internalizados nas pessoas, o que torna o indivíduo ainda mais importante para a organização. Para que o conhecimento existente numa organização seja transformado em mais eficiência e atendimento de qualidade e aos cidadãos, é necessário que ele seja compartilhado e estimulado. 
É premente a necessidade das organizações públicas adotarem modelos administrativos utilizados pelas organizações privadas. É preciso que as pessoas comecem a ter consciência de suas responsabilidades, e como nas organizações privadas o foco é a prestação de serviço de qualidade ao seu público, as organizações públicas também devem saber identificar as necessidades do seu público ou o segmento da população para que determinado órgão público foi criado. Nas organizações públicas, onde o foco deve estar voltado para a sociedade, a gestão do conhecimento deve proporcionar uma constante reavaliação na maneira em que o trabalho tem sido realizado. Os novos conceitos criados devem estar voltados para a maximização na utilização dos recursos e a busca da eficiência e da qualidade na prestação dos serviços.

\section{ANÁLISE DOS RESULTADOS}

A partir da tabulação dos 67 questionários recebidos foram elaborados os gráficos apresentados a seguir, a partir dos quais demonstram como a Instituição se apresenta em relação as condições organizacionais necessárias para a gestão do conhecimento

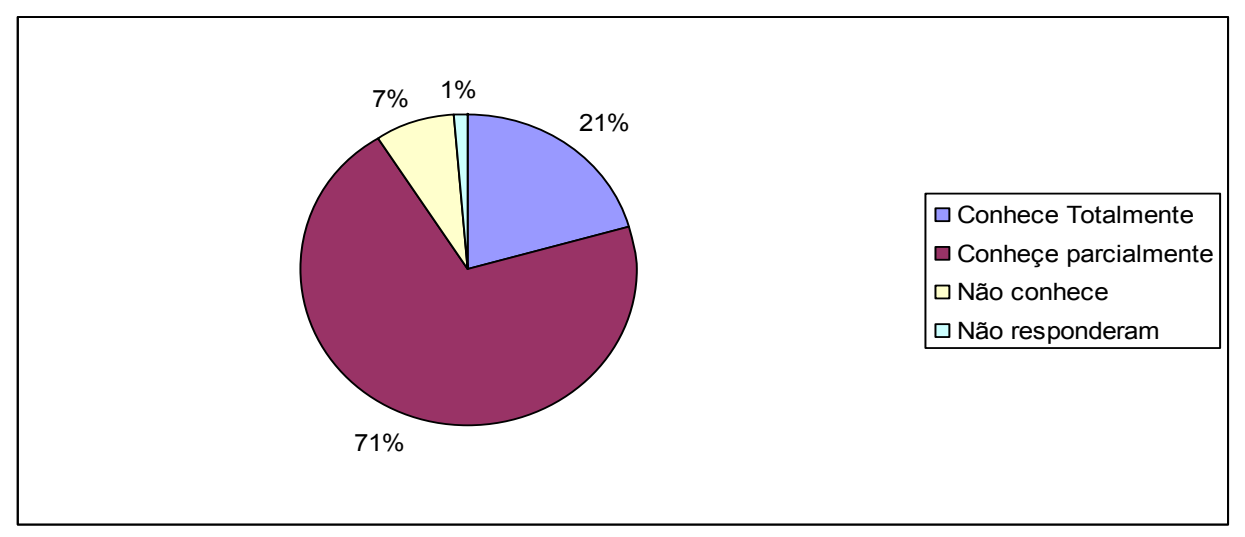

\section{Gráfico 1 - Conhecimento da Missão e Visão da Instituição \\ Fonte: Resultado pesquisa}

De acordo com o gráfico $1,71 \%$ dos pesquisados conhecem parcialmente a missão e visão da Universidade e $21 \%$ conhecem totalmente. Nas organizações voltadas para a criação de conhecimento é fundamental que as pessoas tenham um conhecimento claro da missão e visão da empresa, que na teoria da criação do conhecimento corresponde a Intenção, a primeira condição organizacional para o desenvolvimento da espiral do conhecimento. A Intenção fornece um senso de direção e serve como parâmetro para a justificação dos conceitos criados. Se não existir um conhecimento claro da missão e visão a flutuação e o caos criativos, condição organizacional importante na fase inicial do desenvolvimento de conceitos, fica prejudicada, pois se as pessoas não possuem um senso de direção a flutuação e caos criativos acabam se tornando destrutivo, podendo levar a desordem. 


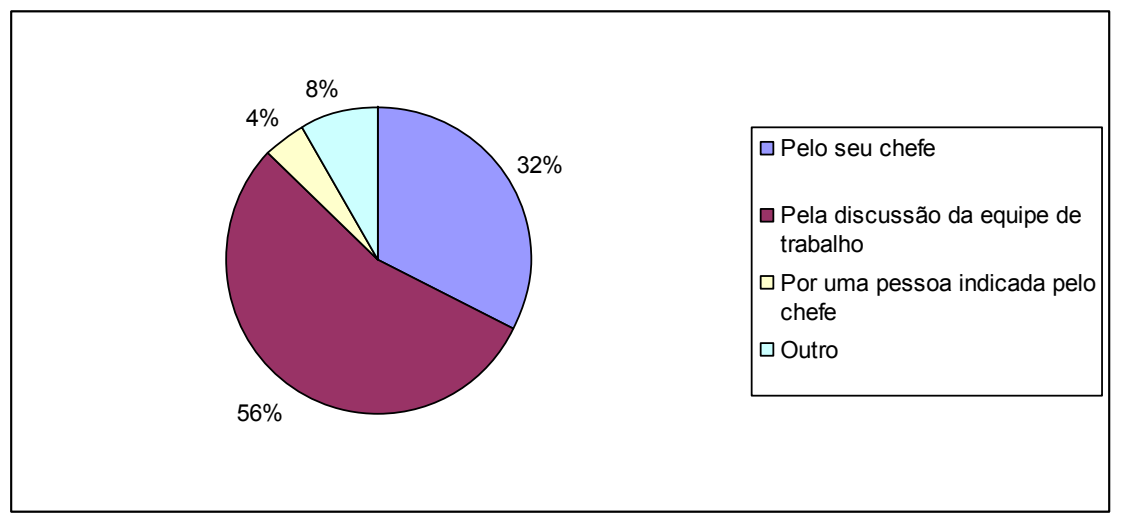

Gráfico 2 - Responsabilidade com o trabalho

Fonte: Resultado pesquisa

De acordo com o gráfico 2, 56\% dos pesquisados responderam que quando surge um determinado problema, este é resolvido a partir da discussão entre colegas, e 32\% responderam que a solução é adotada pelo chefe responsável pelo setor de trabalho.

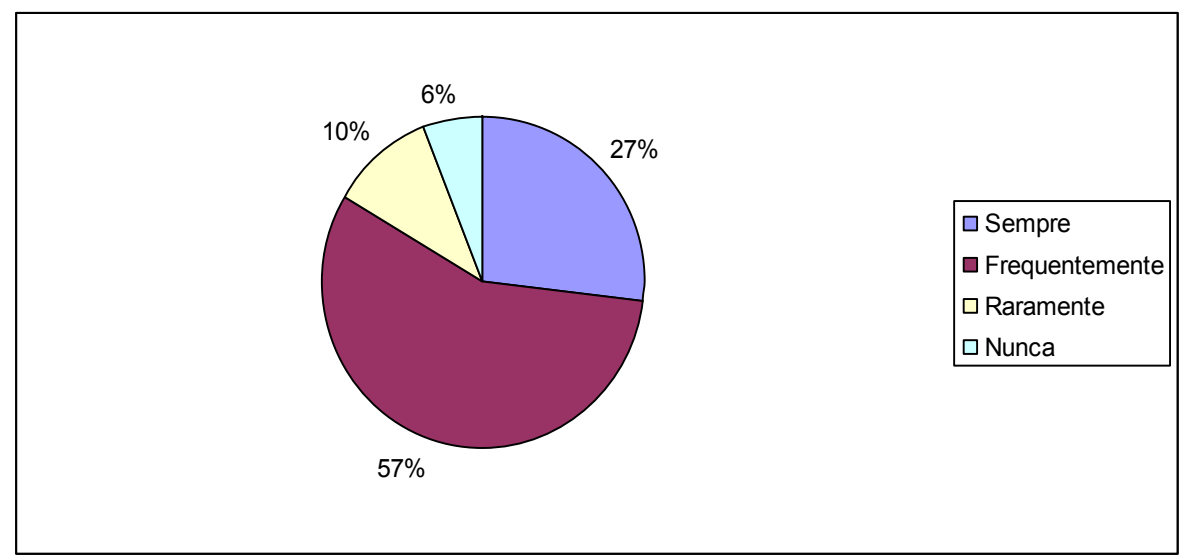

\section{Gráfico 3 - Liberdade para criar}

Fonte: Resultado pesquisa

Os dados do gráfico 3 demonstram que para $57 \%$ dos pesquisados, freqüentemente as pessoas possuem liberdade para utilizar suas criatividades no desenvolvimento das tarefas, e $27 \%$ responderam que sempre podem ser criativos no trabalho.

A partir do gráfico 2 e 3 podemos perceber que a autonomia para a realização das tarefas não está bem definida. Para o desenvolvimento da espiral do conhecimento os indivíduos autônomos é uma das condições organizacional para a criação do conhecimento organizacional. A autonomia é fundamental para que as pessoas possam desenvolver suas criatividades, importante para o desenvolvimento de novos conceitos, e também como fator motivador para as pessoas no ambiente de trabalho. 


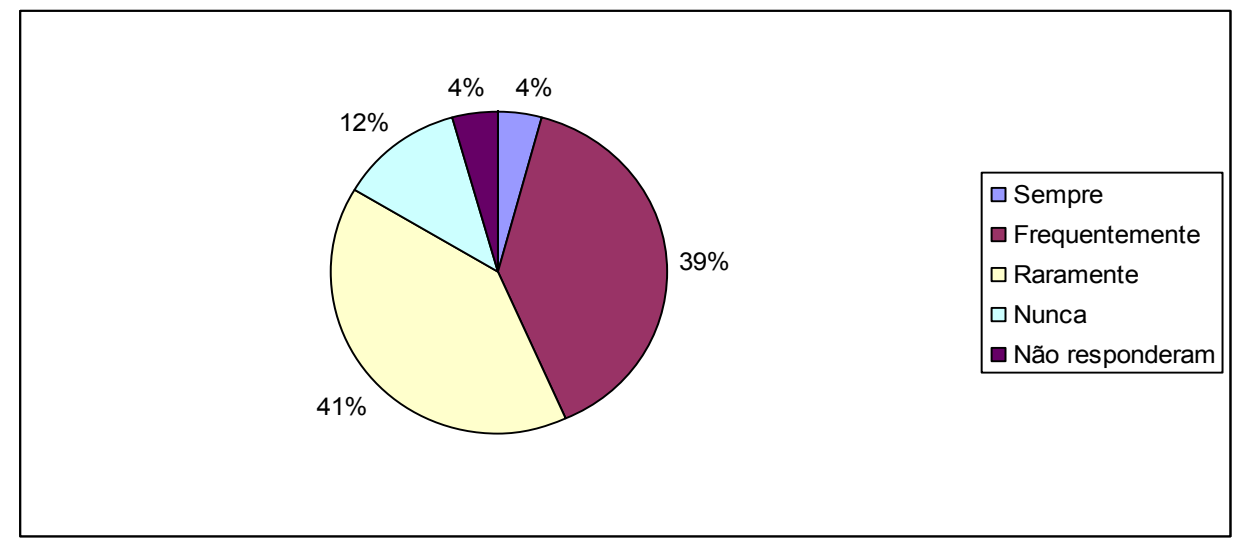

\section{Gráfico - 4 Participação das equipes}

Fonte: Resultado pesquisa

Em relação à participação das equipes com sugestões em relação às decisões dos superiores, 39\% responderam que freqüentemente podem participar, e $41 \%$ responderam que raramente podem colaborar, e $12 \%$ responderam que nunca podem participar. $\mathrm{Na}$ teoria da criação do conhecimento organizacional, a participação das pessoas é fundamental para que o conhecimento tácito seja socializado.

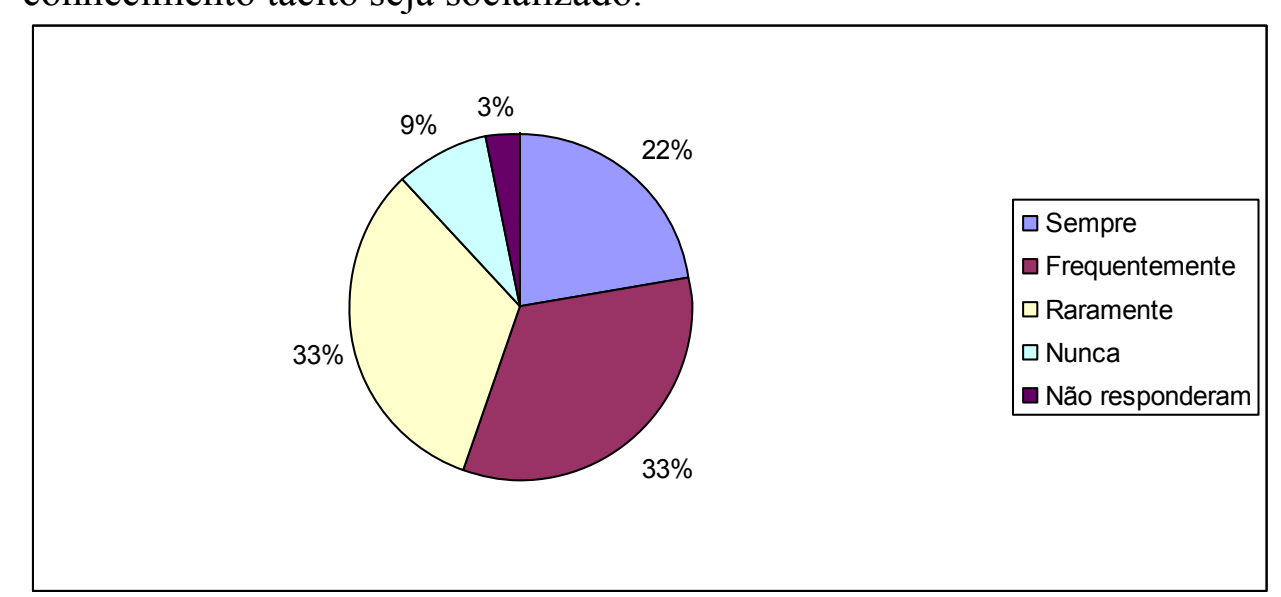

\section{Gráfico - 5 Participação nas reuniões}

Fonte: Resultado pesquisa

Conforme o gráfico 5, 33\% responderam que freqüentemente possuem oportunidade de participar com sugestões nas reuniões, e o mesmo percentual responderam que raramente, $22 \%$ responderam que sempre possuem oportunidade para participar ativamente nas reuniões. A participação das pessoas é fundamental para que estas possam expressar seus conhecimentos e experiências no processo de criação de conceitos ou no desenvolvimento de novas perspectivas para o trabalho. 


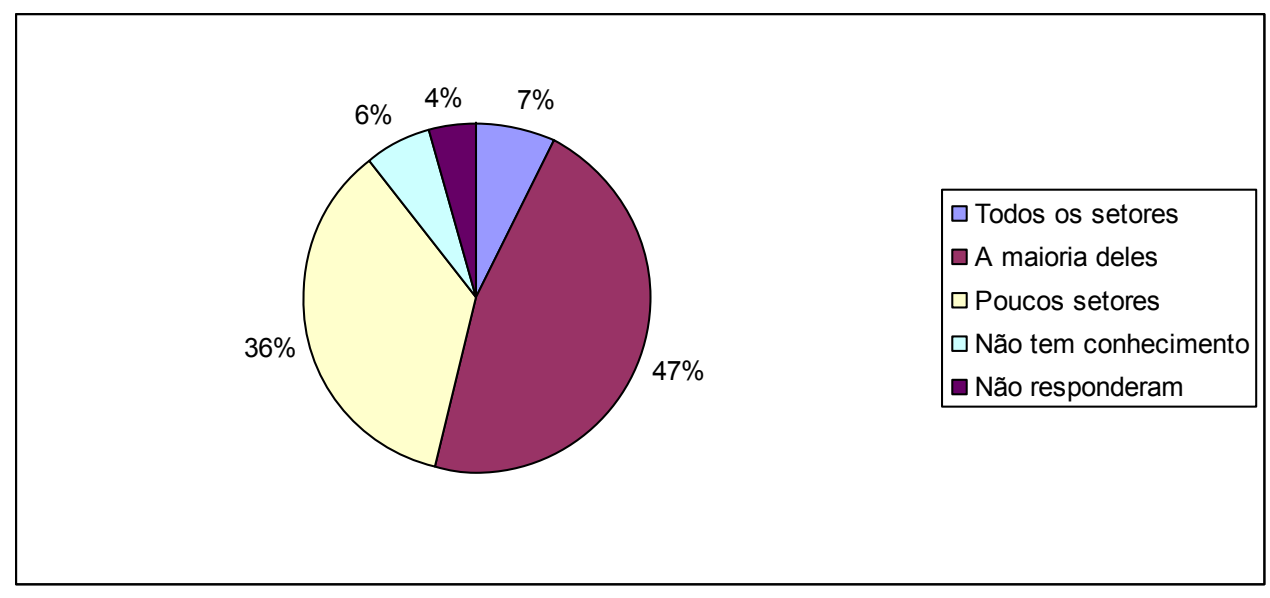

\section{Gráfico 6 - Conhecimento das atividades de diferentes setores Fonte: Resultado pesquisa}

Em relação ao conhecimento que as pessoas possuem das atividades de outros setores, que interferem na realização do trabalho de um determinado setor, $47 \%$ responderam que possuem conhecimento da maioria deles, $35 \%$ conhecem poucos setores. Analisando de acordo com as condições organizacionais, o conhecimento das atividades de outros setores é fundamental para promover a redundância de informações, ou seja, na medida em que as pessoas conhecem as atividades que complementam seu trabalho, aumenta o senso de responsabilidade, e no processo de criação do conhecimento permite o surgimento de idéias criativas, proporcionando a criação de novos conceitos levando a melhorias e a inovação no trabalho.

Os gráficos 4, 5 e 6 demonstram que a socialização do conhecimento tácito não está sendo realizada de maneira adequada. O compartilhamento deste tipo de conhecimento somente se realizará quando as pessoas possuem a liberdade para expressar seus conhecimento e experiências, de maneira espontânea e que as sugestões de todas as pessoas sejam consideradas e analisadas. Com isso a redundância de informações, a terceira condição organizacional para o desenvolvimento da espiral do conhecimento não está sendo promovida ou então não está sendo realizada de maneira adequada. A redundância de informações ocorre quando as pessoas expressam livremente seus pensamentos, e depois, com o auxílio de metáforas e analogias, começam a criar uma imagem sobre o que se está pretendendo desenvolver, e partir da análise e discussões das diversas propostas chega-se a um novo conceito.

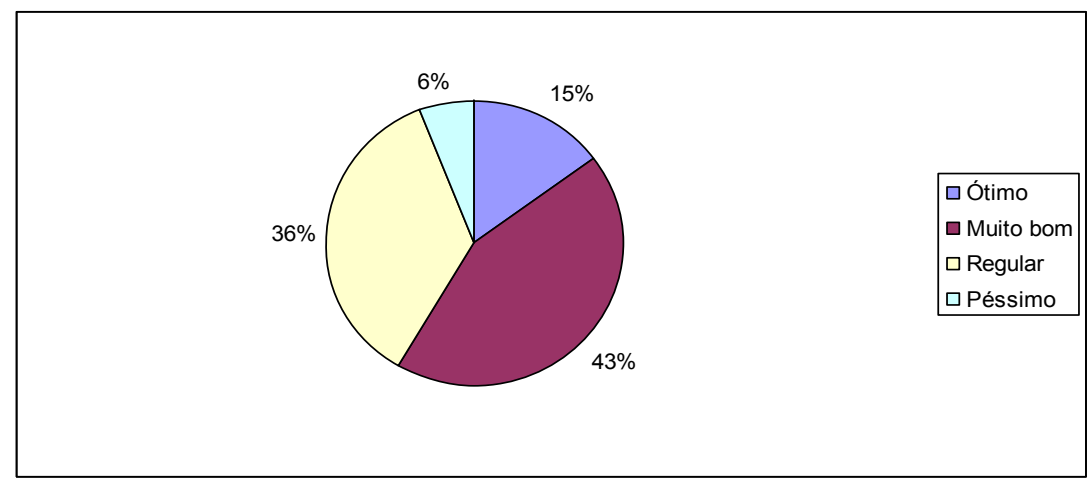

Gráfico 7 - Comunição no setor de trabalho

Fonte: Resultado Pesquisa 
Conforme o gráfico $7,43 \%$ dos pesquisados consideram a comunicação no setor de trabalho muito bom, $36 \%$ regular e $15 \%$ ótima.

Um processo de comunicação eficiente é fundamental para que pessoas possam compartilhar suas habilidades e experiências.

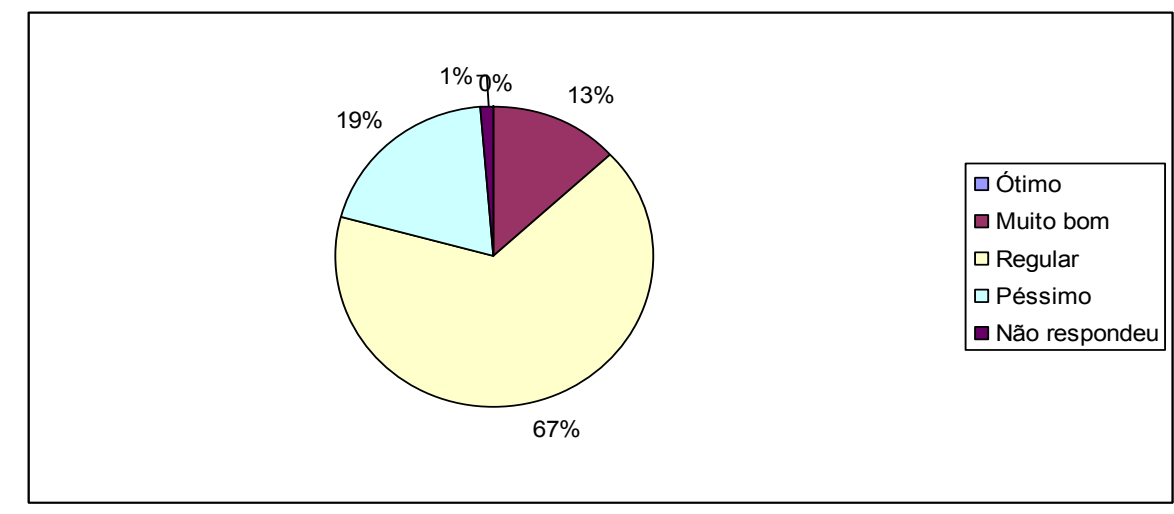

Gráfico 8 - Comunicação entre setores

Fonte: Resultado pesquisa

Em relação a comunicação entre os setores, 67\% consideram regular e $19 \%$ péssima. A partir dos gráficos 7 e 8 verifica-se que a utilização da variedade de requisitos está sendo prejudicada pela falta de um sistema de comunicação eficiente, principalmente entre os setores do Campus da Unioeste. A variedade de requisitos é a quinta condição organizacional para o desenvolvimento da espiral do conhecimento. Para que essa condição faça parte na organização é necessário um sistema de comunicação eficiente entre os diversos setores, para que com isso, os conhecimentos, habilidades e experiências possam ser compartilhadas facilitando o desenvolvimento de novos conceitos. A diversidade interna facilita o atendimento dos desafios impostos pelo ambiente, mas para isso é necessário que as pessoas e setores tenham livre acesso as informações.

\section{CONSIDERAÇÕES FINAIS}

A gestão do conhecimento é um modelo administrativo que proporciona mais agilidade para as organizações. O seu foco é a criação do conhecimento visando a inovação contínua. Em um contexto caracterizado pelas constantes mudanças, a aplicação da gestão do conhecimento faz com que a organização tenha mais flexibilidade, seja mais dinâmica para se adaptar as novas necessidades do mercado. A aplicação da espiral do conhecimento permite que todas as pessoas de uma organização, dentro de sua área de trabalho, socializem seus conhecimentos tácitos em busca da criação de novos conceitos que podem ser para resolver um determinado problema, melhorar a prestação dos serviços ou inovar um determinado processo.

Nas organizações públicas a gestão do conhecimento também pode proporcionar mais agilidade no atendimento, na medida em que mais pessoas começam a avaliar os procedimentos adotados para a realização do trabalho.

A gestão do conhecimento nos órgão público visa o aumento da eficiência, agilidade no atendimento e, sobretudo a prestação de um serviço de qualidade. $\mathrm{O}$ direcionamento deve ser a constante busca da satisfação da população em relação aos serviços prestados. 
Os resultados da pesquisas demonstram que em todas as condições organizacionais há a necessidade de melhorias. Na primeira condição, a Intenção, que corresponde a missão e visão, o resultado da pesquisa demonstra que de maneira geral, as pessoas não tem um conhecimento claro desta. No processo de criação do conhecimento é fundamental que as pessoas conheçam a intenção organizacional para direcionar todas as suas ações para os objetivos propostos, e também para que possam ter parâmetros de avaliação para justificar os conceitos recém-criados.

De acordo com o resultado da pesquisa, o sistema de comunicação, apresenta-se bastante deficiente, principalmente entre os setores do campus Unioeste Cascavel. Um sistema de comunicação eficiente é importante para atender a quinta condição organizacional, ou seja, a variedade de requisitos que proporciona a diversidade de experiências e habilidades, importante para a elaboração de novos conceitos.

A gestão do conhecimento deve ser incentivada em todas as organizações, pois é uma nova proposta que visa à melhoria do ambiente de trabalho e, sobretudo proporcionar maior competitividade. As buscas pela inovação contínua mantêm as organizações concatenadas com o ambiente externo, oferecendo novos produtos ou serviços que atendam as necessidades dos consumidores. Nas organizações públicas, o foco das inovações volta-se para a sociedade, buscando sempre a excelência na prestação de serviços.

\section{REFERÊNCIAS}

ANGELONI, Maria Terezinha. Organizações do conhecimento: infra-estrutura, pessoas e tecnologias. São Paulo: Saraiva, 2002.

CAMPOS, Marcelo Moreira. Gestão do conhecimento na Administração Pública Federal em Brasília: um estudo exploratório. Dissertação de Mestrado apresentada ao departamento de Ciências da Informação e Documentação da Universidade de Brasília. Ano 2003.

COLAUTO, Romualdo Douglas; BEUREN, Ilse Maria. Proposta para Avaliação da Gestão do Conhecimento em Entidade Filantrópica: o Caso de uma Organização Hospitalar. Revista RAC n. 04 outubro/dezembro 2003

DAVENPORT, Thomas. Conhecimento empresarial. Como as organizações gerenciam o seu capital intelectual. Rio de Janeiro: Campus

GIL, Antonio Carlos. Como elaborar projetos de pesquisa. 3 ed. São Paulo, 1991.

NONAKA, Ikujiro; TAKEUCHI, Hirotaka. Criação de conhecimento na empresa. Rio de Janeiro: Elsevier, 1997.

PEREIRA, Frederico César Mafra. O processo de conversão do conhecimento em uma Escola de Atendimento Especializado. Universidade Federal de Minas gerais, 2005.

QUEL, Luiz Felipe. Gestão do conhecimento e os desafios da complexidade nas organizações. São Paulo: Saraiva, 2006.

QUIRINO, Raquel. Saberes do pedagogo para a prática educativa nas organizações

empresariais. Dissertação de Mestrado, centro Federal de Educação Tecnológica - CEFET.

Belo Horizonte -MG, 2005. 
SILVA, Edvaldo Henrique Von Söhsten Cavalheiros da. A Gestão do Conhecimento na Área Pública: proposta para o Tribunal de Justiça-PE. Disponível em: http://www.intempres.pco.cu/Intempres2000-2004/Intempres2004/Sitio/Ponencias/51.pdf. Acesso em 27/04/2009. Ano, 2000.

SENGE, Peter M. A quinta disciplina: arte e prática da organização que aprende. $24^{\mathrm{a}}$ Ed. Rio de Janeiro: BestSeller, 2008.

SILVA, Nanci. Gestão do Conhecimento na secretária de receita e Controle. Disponível em: http://www.sefaz.ms.gov.br/conhecimento/destaques/view.asp?id=14. Acesso em: 26/04/2009. 2005.

TERRA, José Cláudio Cyrineu. Gestão do conhecimento: o grande desafio empresarial. Rio de Janeiro: Elsevier, 2005.

ZABOT, João Batista M. e SILVA, L. C. Mello da. Gestão do conhecimento: aprendizagem e tecnologia: construindo a inteligência coletiva. São Paulo: Atlas, 2002. 